\title{
Produção de energia eólica em Pernambuco e a injustiça ambiental sobre comunidades rurais
}

\author{
Amanda Oliveira de Santana ${ }^{1}$ \\ https://orcid.org/0000-0002-2157-7410
}

\author{
Tarcísio Augusto Alves da Silva ${ }^{2}$ \\ https://orcid.org/0000-0003-2956-3512
}

${ }^{1}$ Universidade Federal Rural de Pernambuco, Departamento de Ciências Sociais, Recife, PE, Brasil

${ }^{2}$ Universidade Federal Rural de Pernambuco, Departamento de Ciências Sociais, Recife, PE, Brasil

Produção de energia eólica em Pernambuco e a injustiça ambiental sobre comunidades rurais Resumo: Encoberta por uma aura verde, formas de injustiça ambiental têm se materializado em experiências de produção de energia eólica. Neste texto, apresentamos como a energia, considerada limpa, produz externalidades negativas que atingem populações rurais, especialmente agricultores familiares. O estudo que forneceu as bases para este trabalho foi realizado por meio de 14 entrevistas semiestruturadas e da observação direta em duas comunidades rurais no município de Caetés, em Pernambuco. Os resultados mostram como processos de expropriação são acionados pelos impactos da presença das torres de aerogeradores no território onde vivem os pequenos agricultores.

Palavras-chave: Energia eólica. Injustiça ambiental. Comunidades rurais.

\section{Abstract: Wind energy production in Pernambuco and environmental injustice on rural communities}

Covered by a green aura, forms of environmental injustice have materialized in experiences of wind energy production. In this paper, we present how green energy, often considered a clean source of power, produces negative external factors that affect rural populations, especially family farmers. The study was carried out through 14 semi-structured interviews, followed by direct observation in two rural communities in the municipality of Caetés, in Pernambuco. The results show how expropriation processes are triggered by the impacts the presence of wind turbine towers cause within the territories where small farmers live. Keywords: Wind energy. Environmental injustice. Rural communities.

Recebido em 21.04.2020. Aprovado em 12.06.2020. Revisado em 16.10.2020.

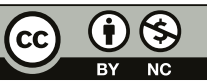

Este é um artigo publicado em acesso aberto (Open Access) sob a licença Creative Commons Attribution NonCommercial, que permite uso, distribuição e reprodução em qualquer meio, sem restrições desde que sem fins comerciais e que o trabalho original seja corretamente citado. 


\section{Introdução}

Em 1987, foi publicada pela Comissão Mundial sobre Meio Ambiente e Desenvolvimento o Relatório Brundtland - Nosso Futuro Comum, responsável por popularizar o conceito de desenvolvimento sustentável (BRUNDTLAND, 1987), sobretudo com a Conferência das Nações Unidas sobre o Meio Ambiente e o Desenvolvimento realizada no Rio de Janeiro, em 1992.

No entanto, essa popularização do conceito e sua aplicabilidade não passaram alheias às críticas que surgiram como resultado das evidências e questionamentos produzidos por diversos campos do saber, como bem expressam os argumentos de Foladori (2001) e Montibeller Filho (2004) ao encararem o desenvolvimento sustentável como um mito. A mesma crítica orienta trabalhos oriundos da Ecologia Política, norteados por estudos e pela ação política dos seus pesquisadores, na investigação dos conflitos ambientais distributivos ao apontarem como as assimetrias de poder definem aqueles a quem os impactos indesejáveis do desenvolvimento devem atingir (LITTLE, 2001; ACSELRAD, 2004; MARTÍNEZ-ALIER, 2007).

Em resumo, as críticas situam como problemática do desenvolvimento sustentável sua confluência com a própria lógica do capitalismo, procurando renová-lo sob uma perspectiva verde, uma vez que tende a responder aos problemas ambientais do crescimento, invocando a técnica em detrimento das relações sociais que engendram os desequilíbrios entre sociedade e natureza. Desse modo, para Foladori (2001, p. 108), “[...] é a forma social da produção e não seu conteúdo material e técnico que determina o comportamento em relação à natureza".

No presente artigo, procuramos articular a mesma argumentação a partir de evidências trazidas da experiência de produção da energia eólica no Agreste pernambucano. Por meio de relatos de pequenos agricultores, residentes da zona rural do município de Caetés, identificamos ações de injustiça ambiental na geração da chamada "energia limpa", uma das respostas técnicas à resolução dos problemas provenientes da necessidade de crescimento e fornecimento de energia.

Assim, este texto tem os seguintes objetivos: a) discutir a problemática da produção de energia eólica no contexto discursivo do desenvolvimento sustentável; b) apresentar a existência de impactos na implantação e funcionamento das torres de energia eólica nas comunidades de Larguinha e Pau Ferro, no munícipio de Caetés, segundo a perspectiva dos(as) agricultores(as); e d) mostrar como essas comunidades convivem com a produção de energia eólica em seus territórios.

Os resultados do estudo decorrem da realização de entrevistas semiestruturadas com 14 residentes, tomando como critério de seleção a sua participação na produção da agricultura familiar nas localidades estudadas. Além disso, utilizamos a técnica de observação direta nos espaços de vivências das comunidades para validar parte dos dados coletados no processo de entrevista, como também exploramos informações disponibilizadas no site da empresa Casa dos Ventos e noticiários.

\section{Injustiça ambiental e a dimensão excludente da relação sociedade e meio ambiente}

É muito comum encontrarmos situações em que comunidades pobres, e desprovidas de capital político suficiente, são submetidas a todo tipo de expropriação de seus territórios, devido às decisões locacionais de instalação de fontes poluidoras, como alguns tipos de indústria, ou à definição de locais de despejo de lixo, tóxico ou não, em áreas cuja população é negra, indígena, camponesa ou pobre.

Uma vasta literatura científica vem comprovando e dando visibilidade a diversas situações em que as baixas condições socioeconômicas e a vivência étnica e de cor são listadas como critérios locacionais para instalação desses empreendimentos, seja público ou privado, nas proximidades onde vivem tais populações. Um exemplo claro desse fenômeno deu início às primeiras denúncias de injustiça ambiental externalizadas em casos de racismo ambiental, nos Estados Unidos, na década de 1980, pelo reverendo Benjamin Chavis. Seu ativismo permitiu dar visibilidade à escolha deliberada de instalações de depósitos de rejeitos tóxicos e do funcionamento de indústrias poluidoras em um dos locais mais pobres da Carolina do Norte, onde, historicamente, se estabeleceram comunidades descendentes de escravos.

A injustiça ambiental é, portanto: 
[...] o mecanismo pelo qual sociedades desiguais, do ponto de vista econômico e social, destinam a maior carga dos danos ambientais do desenvolvimento às populações de baixa renda, aos grupos sociais discriminados, aos povos étnicos tradicionais, aos bairros operários, às populações marginalizadas e vulneráveis (PORTO, 2004, p. 122).

Para além da experiência estadunidense, as situações de injustiça ambiental se fazem presentes em vários outros países e, mais especificamente, naqueles em que a manutenção e ampliação de investimentos sugerem a desterritorialização, ou a degradação dos espaços de vida, de populações tradicionais, como acontece onde as políticas neodesenvolvimentistas fornecem elementos para o avanço da área de mineração, produção de energia, construção de barragens e agronegócio.

Na região da Mata Norte de Pernambuco, havíamos identificado fenômeno similar com a instalação de um aterro sanitário nas proximidades de um assentamento rural, localizado entre os municípios de Goiana, Itaquitinga, Itapissuma e Igarassu. Naquele estudo, a análise dos documentos e dos processos de definição locacional do empreendimento demonstrou que, entre sete opções de localização para construção do aterro, estava aquela em que o avizinhava ao local onde a comunidade de pequenos agricultores dispunha para morar e trabalhar (SILVA, 2010).

Um elemento central nessa discussão indica que a distribuição desigual dos efeitos de danos ambientais que afetam, com mais rigor, grupos sociais menos favorecidos ou minorias étnicas demonstra que a transferência dos custos ambientais para as partes mais débeis é um exercício de expropriação dos recursos naturais, beneficiando certos grupos em detrimento de outros (MARTíNEZ-ALIER, 2007).

Dessa forma, as desigualdades estruturais e fundantes da sociedade capitalista fortalecem processos de injustiça ambiental e trazem para a arena da crise ecológica as assimétricas correlações de forças em torno das disputas por recursos e amenidades ambientais (tais como ar puro, áreas verdes e água limpa), além da distribuição desigual dos efeitos negativos da lógica de produção capitalista globalizada.

\section{A geração de energia limpa: um lobo em pele de cordeiro}

Os problemas que atingem as populações pobres, étnicas, quilombolas, ribeirinhas, camponesas e de pequenos agricultores não estão restritos apenas às ações de indústrias poluidoras ou de equipamentos públicos instalados nas proximidades ou dentro dos próprios territórios. São muitos e diversos os empreendimentos que, ao identificarem os elementos necessários à exploração econômica de matérias-primas como a terra, a água, o vento, a vegetação ou os minérios no lugar onde vivem essas comunidades, iniciam uma série de investidas para acessar esses recursos, independentemente do valor ou de sua representatividade para a existência material e imaterial dessas populações.

Nesses casos, há um forte apelo ao discurso técnico fazendo apologia aos benefícios e segurança na realização daquela atividade econômica. Essa retórica é utilizada como forma de se sobrepor às necessidades daqueles que têm na relação direta com a natureza, em muitos casos, sua única e exclusiva fonte de sobrevivência. Observam-se, assim, demandas de uma sociedade genérica sendo utilizadas como justificativa para exploração dos recursos naturais e desterritorialização das comunidades. O lugar dos mais pobres e vulneráveis, nessa trama, seria o de suportar as externalidades que lhes são impostas por aqueles que veem essa mesma natureza apenas como fornecedora dos recursos necessários à produção de riqueza.

Ao invocar as demandas de uma sociedade genérica e os benefícios de determinada atividade econômica para ela é que podemos notar como os interesses sobre um território, até então deslocado das preocupações e investimentos financeiros, são transformados em prioridades econômicas por outsiders. Embora seja cada vez mais desgastante se contrapor a essas iniciativas, quando elas assumem a roupagem de estratégias do desenvolvimento sustentável, como é o caso da geração de energia limpa, o nível de dificuldade para enfrentamento do impacto, da instalação e do funcionamento do empreendimento se torna ainda maior.

A razão instrumental presente na lógica de inovação tecnológica, prevenção, participação pública na tomada de decisão e soluções ambientais e econômicas simultâneas é o ancoradouro das estratégias desenvolvidas no âmbito da chamada teoria da modernização ecológica ${ }^{1}$, norteadora de muitas práticas e discursos sobre desenvolvimento sustentável. No entanto, é sob a batuta dos interesses do capital que essa fórmula mágica 
procura dissipar posicionamentos antagônicos aos seus interesses, demonstrando que nas soluções técnicas aos problemas ambientais estariam as saídas para os desequilíbrios ecológicos.

Não obstante esse argumento, encontra-se ainda a utilização de ferramentas democráticas, como as audiências públicas, que se fariam presentes no processo para atestar a lisura e boas intenções dos projetos que invocam a participação popular na tomada de decisão. Hanningan (2009) analisa essas audiências e as denomina de arenas sociais de risco, em que a dimensão da informação chega a ser absorvida, mas não impacta ou exerce influência sobre a definição real do risco, tornando a participação de agentes com menor capital cultural e político sempre periférica.

Desenvolvimento sustentável e modernização ecológica seriam, portanto, as faces de um mesmo processo, ou seja, aquele que reconhece as dificuldades, impactos e problemas gerados pela ideia de crescimento ilimitado, mas que atribui as suas causalidades e seus efeitos à dimensão da limitação técnica da produção e do conhecimento. Logo, a correção dessa instabilidade se daria apresentando respostas também técnicas e depositando confiança no desenvolvimento científico e tecnológico, que produziu muitos desses problemas.

Sob esse prisma, o pano de fundo da crise ambiental se mantém intocado, ora porque se pode, inclusive, apontar a própria natureza como causadora dos desequilíbrios ecológicos (vide alguns posicionamentos que explicam a mudança climática a partir de movimentos de aquecimento e esfriamento de temperaturas, próprios da dinâmica terrestre), ora porque seria ainda possível culpabilizar a pobreza, mas nunca o próprio capitalismo, por nossos males de origem.

O desenvolvimento tecnológico, amparado por um discurso ecológico, promoveria processos inovativos para desenhar, assim, tecnologias limpas em substituição das fontes poluidoras, permitindo atenuar, ou mesmo reverter, as marcas negativas do desenvolvimento e garantir, ao mesmo tempo, que as regras do consumo e do crescimento econômico se mantenham dentro dos padrões aceitáveis para a reprodução do capital.

Entretanto, na prática, a modernização ecológica, ao não considerar a dimensão social na relação sociedade e meio ambiente, continua a respaldar os vários casos em que o acesso aos recursos naturais se dá ratificando as estruturas sociais desiguais. Porém, a implementação de uma sociedade baseada em princípios de sustentabilidade deveria recusar-se a "[...] enfrentar a crise ambiental sem promover a justiça social" (ACSELRAD, 2004, p. 33).

Isso significa que a sustentabilidade deve apontar para o respeito e interesse das comunidades ou populações, sejam elas formadas por grupos étnicos e raciais ou compostas por indivíduos de baixo poder aquisitivo, em projetos econômicos que envolvam suas vidas. Suas características sociais, culturais e econômicas devem, sim, ser consideradas como critérios, mas para que sejam protegidas e tenham seu acesso aos recursos naturais amplamente respeitado e inalterado.

Assim, não parece lógico que a natureza deva se adequar aos interesses das empresas, e sim o contrário: os projetos econômicos deveriam condicionar-se aos seus tempos e movimentos. Essa é uma equação bastante complicada de ser resolvida em nosso atual estágio civilizatório, quando temos testemunhado a natureza precisando se subordinar, constantemente, aos negócios e empreendimentos, pelo lobby exercido por empresas junto aos governos no sentido de alterar a legislação ambiental ou pela ausência de fiscalização que conduz às formas de burlar a lei.

No caso específico da energia eólica, o estudo realizado por Neri et al. (2019) no semiárido pernambucano demonstra como isso tem ocorrido com o choque entre os planos de expansão do setor e as metas de conservação na Caatinga brasileira. Para os autores, não seria de se estranhar que essas empresas operem politicamente contra a proteção de áreas de Caatinga, porque a ampliação e a manutenção dessas áreas aumentariam seu custo de estabelecimento ou até dificultariam sua expansão.

Apesar de muitas considerações a respeito dos impactos ambientais da geração de energia eólica estarem voltados aos problemas da fauna e da flora, não é difícil localizar como ela interfere no dia a dia das comunidades rurais.

Como, em geral, a geografia dos investimentos nessa atividade está centrada em áreas distantes de grandes centros urbanos, o desdobramento de sua externalidade negativa tem sido sentido por muitas populações que vivem no campo. Por isso, ambientalistas têm apontado a necessidade de acompanhar mais de perto a implantação dos parques eólicos e o assessoramento das comunidades que são afetadas pela presença desses empreendimentos em suas propriedades, nas proximidades de suas residências e locais de trabalho, levando em consideração, entre outros motivos, o fato de, em geral, a população rural possuir baixa escolaridade e ser 
composta por um bom número de pessoas acima dos 50 anos de idade, favorecendo as investidas contra elas, especialmente no que tange à expropriação de seus territórios.

Como aponta Costa (2018), a geração de energia eólica é um negócio de "peixe grande", visto que em sua composição estão empresas ligadas ao setor financeiro, fundos de pensão, grandes investidores estrangeiros, grandes corporações, associando-se a empresários nacionais, em alguns casos. Esse fato, além de denunciar o distanciamento dos interesses desses grupos das demandas e dinâmicas locais, salienta a utilização dos recursos naturais por uma perspectiva unicamente voltada aos lucros dos acionistas e à instrumentalização da natureza para essa finalidade.

$\mathrm{Na}$ análise dos impactos sociais sobre o conjunto das comunidades rurais, uma extensa literatura tem apontado para um processo moderno de esbulho de terra, operado sob vias legais por meio de contratos de arrendamento. Ocorre que esses contratos apresentam algumas cláusulas que retiram a autonomia dos moradores de suas terras e o direito de uso dos seus territórios tradicionalmente ocupados, negando ou dificultando a prática da agricultura e pecuária no território (COSTA, 2018; TRALDI, 2019). Os prazos de vigência desses contratos são outro fator de preocupação, pois impõem o arrendamento a, pelo menos, uma nova geração de pequenos proprietários nas condições ali contratadas, tendo em vista que os prazos vão de 20 a 50 anos, a depender da situação. Destaca-se ainda, segundo Porto, Finamore e Ferreira (2013, p. 52), que, no caso dos quilombolas, eles “[...] são pressionados a assinar como confrontantes da empresa, moradores e lideranças são assediados com protocolo de intenção, o que causa a divisão no interior das comunidades".

Aquilo a que nos referimos como processo moderno de esbulho de terra compreende os mecanismos legais utilizados pelas empresas com a finalidade de reduzir os direitos sobre a propriedade arrendada, definindo um conjunto de obrigações desiguais entre as empresas e os pequenos proprietários de terra, de forma a retirarlhes a autonomia sobre ela.

Por sua vez, utilizando o termo inglês green grabbing, os autores Fairhead, Leach e Scoones (2012) demonstram em escala mundial como, além da terra, outros recursos naturais têm sofrido apropriação privada legitimada pelo discurso da proteção do meio ambiente ou financiada por mecanismos relacionados à mitigação das mudanças climáticas.

Em vários estados nordestinos (BA, RN, $\mathrm{CE}, \mathrm{PE})$, verifica-se a replicação de uma mesma lógica de impactos sociais, o que nos faz entender que existe um modus operandi, ou receituário, seguido pelas empresas ao se valerem das condições sociais nas quais as populações estão inseridas. É assim que, na fase de construção e instalação de empreendimentos de energia eólica, a presença de operários nas comunidades onde as torres são instaladas gera situações de violência e aumento da prostituição, o que contribui ainda mais para que o discurso do ambientalmente correto revele práticas socialmente injustas.

À medida que os impactos se avolumam, não é de se estranhar que ocorra outro fenômeno, velho conhecido das comunidades rurais: a migração campo-cidade. Aspectos como esse devem ser mais bem investigados a fim de que se tenha uma compreensão mais exata do alcance dos impactos da produção de energia eólica sobre populações tradicionais, principalmente. Nesse sentido, é possível afirmar que, embora haja similaridades, os impactos variam conforme as características locais de onde está inserida cada comunidade.

Muito desse expediente será apresentado a seguir, demonstrando que o conceito de geração de energia limpa aplicado à experiência de empresas de energia eólica pode se revelar como o conto do lobo em pele de cordeiro.

\section{Injustiça ambiental na geração de energia eólica: o caso Caetés, em Pernambuco}

O Nordeste obteve, em 2018, o melhor rendimento em produção de energia eólica no Brasil, representando 85\% do total gerado no País, segundo a Associação Brasileira de Energia Eólica (ABEEÓLICA). Esse resultado é fruto de uma política que tem impulsionado, desde 2009, um grande aporte de investimento para a região com a finalidade de garantir a geração de energia movida pelos ventos. Foi investido entre 2009 e 2017 um montante de $\mathrm{R} \$ 80$ bilhões, referentes a $80 \%$ de todo o valor investido nacionalmente (O CASTIGO..., 2018). A justificativa para tal decisão se baseia no fato de que a região possui características naturais favoráveis à exploração e desenvolvimento do setor, como clima, relevo, latitude e velocidade dos ventos. 
No caso específico de Pernambuco, 18 municípios contêm grande potencialidade de exploração e, até maio de 2018, o estado possuía 35 parques eólicos instalados. Já em 2020, as empresas que exploram as forças dos ventos se faziam presentes em municípios do Sertão (Araripina, Taracatu) e do Agreste pernambucano (Paranatama, Caetés, Pedra, Venturosa, Gravatá, Macaparana, Pombos e Poção).

A produção de energia eólica se coloca como vantajosa porque gera postos de trabalho local (ao menos no processo inicial de construção das torres de aerogeradores), apresenta baixa emissão de CO2 (20,58 milhões de toneladas de $\mathrm{CO} 2$ foram evitadas em 2018), e se caracteriza como fonte inesgotável e limpa de energia, pois reduz a dependência de combustíveis fósseis e por ser o vento um recurso abundante e renovável (BLOOMBERG NEW ENERGY FINANCE; MINISTÉRIO DA CIÊNCIA, TECNOLOGIA E INOVAÇÕES; ASSOCIAÇÃO BRASILEIRA DE ENERGIA EÓLICA, 2018). Um dado a ser destacado nessa forma de produção de energia por seus defensores é o de que ela possibilita, nas áreas rurais, onde as torres são instaladas, que o(a) trabalhador(a) continue a explorar a agricultura e a pecuária. No entanto, há bastante controvérsia quanto a essa afirmação, uma vez que na prática existem limites impostos pelas empresas e pela própria legislação (TRALDI, 2019). Além disso, como mostraremos, a agropecuária é afetada pela instalação dos aerogeradores.

O município de Caetés, localizado no Agreste, com sete usinas, representa 1,3\% da capacidade de geração de energia eólica instalada em todo o território pernambucano. Ele compõe, juntamente com Pedra e Paranatama, o chamado complexo Ventos de Santa Brígida, de propriedade da empresa Casa dos Ventos. Podemos citar várias empresas que atuam em Pernambuco, como o grupo Votorantim Energia, na cidade de Araripina; PEC Energia, em Paranatama; Eólica Quatro Ventos S.A, em Macaparana; Eólica Ouro Branco 2 S.A, em Poção; além da Casa dos Ventos, em Caetés, Pedra, Paranatama e Araripina.

Caetés é um dos municípios de Pernambuco cuja população rural ainda supera a urbana (PERNAMBUCO, 2007). Nele, estão localizadas duas comunidades rurais que ocupam área contígua onde foi inaugurado, em setembro de 2015, parte do Complexo Santa Brígida. Logo de imediato, um dos primeiros problemas trazidos pelo empreendimento estava associado à ocupação crescente de grandes áreas para instalação dos aerogeradores em locais de produção da agricultura familiar.

Segundo revela Traldi (2019) em sua análise sobre o Atlas Eólico e Solar de Pernambuco, uma espécie de mapa da mina para geração de energia limpa, o documento exclui das áreas de exploração: terras indígenas, quilombolas, áreas de conservação e preservação ambiental, aglomerados urbanos e cursos de água. No entanto, mantém as áreas de assentamento rural fora desse grupo, por considerar a possibilidade de os agricultores obterem o título da terra, após dez anos. Nesse caso, as áreas de assentamento caracterizam-se como zonas de "bota fora" para produção de energia limpa e suas externalidades negativas.

A começar pelos contratos de arrendamento, algumas entidades (Sindicato Rural, Articulação Eólicas de Pernambuco) denunciaram a celeridade com a qual estes eram firmados, além das cláusulas impostas aos arrendadores. Embora o valor pago pela presença de torres nas propriedades seja interessante, segundo relatam alguns entrevistados, outros revelam descontentamento, pois afirmam que os valores variam conforme a própria produção das torres. Por exemplo, de acordo com o relato do entrevistado 1, quem arrendou a terra recebe todo mês: "Quando ela [a torre] está rodando, está ganhando. Agora, quando ela está parada, tá no zero". Nesse caso, o arrendamento seria pela produção da torre, e não pela terra arrendada, significando que o proprietário deve dividir com a empresa arrendatária os riscos econômicos da atividade. Apesar de não termos conseguido acesso aos contratos, acreditamos que uma das cláusulas deve fazer referência a isso.

Embora a literatura aponte para uma forma de "expropriação dos sentidos da população atingida" (ACSELRAD; MELLO; BEZERRA, 2009, p. 81), implicando na omissão de informações em situações de injustiça ambiental, no processo de instalação das torres do caso estudado foi possível verificar que a maioria dos entrevistados foi comunicada pela empresa do que seria ali construído. Por outro lado, ficou evidente para os moradores que as informações não foram suficientemente claras quanto às letras minúsculas dos contratos e tampouco quanto a distância das residências em relação às torres. "A distância das torres para as casas, eles não disseram... só falaram que era até 150 metros. Depois que montaram, o povo ficou tudo prejudicado, pois soubemos que era 250 metros" (Entrevistado 5). Esse fato fez com que algumas famílias tivessem que ser retiradas para outro local, tendo em vista a proximidade de suas residências com as torres.

"A promessa foi que, se acontecesse alguma coisa, alguma casa rachasse, eles recuperavam o prejuízo" (Entrevistado 7). Nesse relato, o entrevistado apresenta uma promessa cumprida da empresa, conforme 
verificamos in loco. Todavia, a reincidência do problema parecia, para os moradores, tão frequente quanto o barulho que eles têm que vivenciar cotidianamente, após a chegada da empresa.

Assim, embora haja registros nas entrevistas de que a empresa havia prestado informações sobre os impactos da obra, o certo é que os entrevistados se demonstraram pouco conhecedores da extensão desses impactos.

[...] eu não sabia que ia ser desse jeito, né? Aí depois outro rapaz veio e falou que ia ser assim e mostrou as fotos, mas assim eu não sabia e acho que ninguém sabia que tinha tanto barulho, né? Pensava que era uma coisa mais silenciosa. Mas a gente sabia que já vinha, mas não sabia que ia ser esse impacto [...]. (ENTREVISTADO 3).

[...] eles vieram aqui, a primeira equipe, e levaram o projeto para quem quisesse, né? Disseram como era, mas só que eles não disseram tudo. (ENTREVISTADO 5).

Vinha uma turma, né? Traziam uma explicação de um jeito, depois já vinha outra com eles, e aí prejudicava... Eu não tinha terra, porque não era proprietário do terreno, era do meu pai, não ia responder nada de um terreno que não era meu, né? Se fosse meu, eu não tinha assinado, né? (ENTREVISTADO 8).

A partir da dimensão do conhecimento sobre o processo de instalação das torres, conseguimos identificar a constituição de dois grupos entre os moradores. O primeiro seria formado por parte dos agricultores que teve suas terras arrendadas e, com isso, usufrui de um valor monetário. Aqueles que pertencem a esse grupo se apresentam como mais informados e conhecedores do processo. Já o segundo é composto por residentes que não foram contemplados com o arrendamento, uma vez que suas residências ou propriedades se encontravam distantes da área de impacto imediato das torres.

A constituição desses dois grupos revela uma certa animosidade e desconfiança entre os moradores, pois para muitos o primeiro convive com o problema provocado, por exemplo, pelo barulho, mas recebe uma compensação monetária por isso. Já a situação do segundo grupo pode ser expressa no seguinte depoimento: "Para quem ganhou torre, ganhou real (risos). Eu só fiquei com o barulho mesmo, graças a Deus" (Entrevistado 3). O mesmo pode ser verificado na fala da entrevistada 10: "Só para quem tem torre. Quem não tem, eles não pagam, não [...]. Quem não tem não recebe nada, recebe só o incômodo, né? Que é a zoada" [barulho].

No entanto, entre os dois grupos as queixas em torno do problema produzido pelo som das hélices são a expressão mais permanente das dificuldades vividas com a presença das torres. Há de se considerar que para medir o impacto do som produzido no local se deve levar em conta o silêncio a que anteriormente estavam habituadas as populações rurais ali presentes. Esse infortúnio, por sua vez, é provocador de toda forma de estresse humano, como relata uma das entrevistadas. "É dor de cabeça quase todo dia, você toma uma farmácia quase todinha de dipirona e não passa, e eu não sei, não... Deve ser por causa delas [as torres], né? Porque a gente não sentia isso antes" (Entrevistada 14). Do mesmo modo nos revelou tal problema a entrevistada 10: "A gente vivia sossegado, aí de repente esse barulho. O ouvido; a cabeça começou a doer, e as crianças a chorar. Meu marido achou que eu ia enlouquecer, porque eu dormia com algodão dentro do ouvido".

Esses relatos demonstram que as amenidades locais, como a proximidade em relação à natureza, o clima frio e o silêncio, foram alteradas pela presença das torres de aerogeradores. $\mathrm{O}$ estresse provocado pelo barulho tende a atingir não apenas os seres humanos. Relatos dos moradores apontam para mudanças nos ritmos da produção de milho e para a redução da quantidade de oferta de leite dos animais e ovos das galinhas de terreiros nas pequenas propriedades.

No entanto, embora o barulho apareça como o grande problema a impactar o bem-estar da comunidade, as residências mais próximas das torres ainda suportam outro inconveniente: a sombra produzida pelas hélices. "À tardezinha ela fazia umas sombras, aí aquelas sombras foram me dando tontura, enjoo..." (Entrevistado 4). Da mesma forma, assevera o entrevistado 6: "É uma sombra que incomoda... Você deita incomoda, se você está assistindo [TV] incomoda".

Nota-se no caso Caetés a agenda ambiental sendo o principal impulsionador da propaganda em torno dos benefícios da geração de energia eólica, no entanto, sem revelar as inconveniências provocadas às populações que vivem e habitam os territórios que foram incorporados pelas empresas por um processo de green grabbing, pois, de diferentes maneiras, a remoção de habitantes locais ou a redução drástica de seus direitos e práticas 
de uso da terra e de recursos naturais são subjugadas em nome do interesse de um bem maior nacional ou global (FAIRHEAD; LEACH; SCOONES, 2012).

Se fossem pensados os benefícios que a produção de energia eólica trouxe à comunidade, seriam resumidos às reformas das residências impactadas pela operação das torres, aberturas de estradas próximas a elas, trabalho temporário, pagamento do arrendamento das terras (para o primeiro grupo de residentes), construção de uma pequena e precária praça, construção de uma quadra e assistência social esporádica. Como relatam alguns dos entrevistados: "Fizeram praça, aquela praça que vocês passaram, e estão construindo uma quadra" (Entrevistada 2); "Fizeram uma casa modelo ali, aí disseram que vão fazer parecidos com ela, só vão mudar algumas coisas" (Entrevistado 3); "A promessa foi que, se acontecesse alguma coisa, alguma casa rachasse eles recuperavam o prejuízo [...]” (Entrevistado 7).

Esses aparentes benefícios, por outro lado, funcionam como forma de remediação aos riscos e impactos da atividade de exploração de energia eólica nas comunidades estudadas.

Sobres esses riscos, em julho de 2019, a hélice de uma das torres, localizada na comunidade de Pau Ferro, simplesmente quebrou e caiu, sem que as causas fossem notificadas à comunidade (PARTE..., 2019). O êxodo rural provocado pelo funcionamento das torres eólicas é um dos aspectos a ser analisado sobre os impactos dessa produção de energia nas comunidades rurais estudadas. Embora sejam necessários maiores aprofundamentos sobre o fenômeno, foi possível verificar, no trabalho de campo, várias menções dos agricultores à saída de pessoas para a cidade e pretensões a respeito disso:

Entrevistado 1: Saiu muita gente, foram embora para Caetés.

Entrevistado 2: Minha comadre foi que teve um tempo que ela queria sair, porque ela disse que não aguentava a zoada das torres.

Entrevistado 4: Já saiu um bocado de gente daqui.

Entrevistada 5: Se eu achar um canto bom que nem o meu terreno, para minhas plantas, eu saio. Só não vou destruir o que é meu para ir andar pelo mundo, né?

Entrevistado 6: Não. Ainda não, mas estão pretendendo.

Entrevistado 8: Tem gente querendo agora.

Entrevistado 8: Saiu meu tio... dois tios meus.

Entrevistada 10: Olha, só não foram embora porque não têm condições e não têm para onde ir, mas, se tivessem, as pessoas já tinham ido, já tinham saído.

Entrevistado 13: Eles estão dizendo que vão reformar as casas, né? Outros não querem. Nós queremos a indenização, né? Para sair fora...

Entrevistada 14: O tio dela mesmo pegou quatro torres numa terra dele, e ele saiu...

Isso ratifica o que constatam Fairhead, Leach e Scoones (2012) ao analisarem os processos de apropriação, desapropriação e valorização da natureza, pois, embora assumindo formas diferentes em lugares diferentes, as populações rurais são deixadas em condição de vulnerabilidade generalizada quando suas terras e recursos permanecem abertos à apropriação de outros para fins ambientais. A mesma compreensão foi dada por Wanderley (2004), demonstrando como a antiga precariedade social dos espaços rurais no Brasil tendeu a reforçar os processos de expropriação de populações rurais em relação aos recursos naturais e aos territórios a que estas se encontram circunscritas.

Como se vê, o fenômeno do êxodo rural expressa uma das faces mais cruéis da injustiça ambiental produzida pela força com que se expande, com incentivos públicos, a geração de energia eólica em nosso país. Capturado pela lógica do mercado, via Mecanismos de Desenvolvimento Limpo (MDL), o discurso ambiental é utilizado como justificativa para rebaixar as condições de vida e promover a expropriação das populações rurais.

Mesmo não havendo registro em nosso estudo sobre formas de resistência e conflitos relacionados às duas comunidades e à empresa, ao menos nos anos que se seguiram após sua inauguração, em 2015, há relatos entre os agricultores de ações na justiça que foram favoráveis à empresa. Isso reforça a ideia de que nos 
contextos de ambientalização de práticas econômicas se torna muito mais fácil para as empresas deslegitimar a resistência camponesa colocando-a em oposição ao bom senso do desenvolvimento sustentável.

\section{Considerações Finais}

Na defesa da sustentabilidade ambiental, várias práticas econômicas têm sido desenvolvidas reforçando o ideal de desenvolvimento sustentável como dimensão válida à superação dos efeitos deletérios que o crescimento econômico gerou. A produção de energia eólica tem sido um dos grandes símbolos desse processo, principalmente porque se vale da narrativa de que é um tipo de energia limpa. O fato, porém, é que essa atividade vem afetando comunidades de agricultores que sentem mudanças drásticas em sua rotina e ao mesmo tempo não se veem protegidas pelo Estado, tampouco pelos empreendimentos que se instalam nas proximidades de suas propriedades.

Como afirmamos, uma forma de esbulho moderno se faz presente nas estratégias com as quais os empreendimentos de energia eólica são implantados. Nesse caso, quando por vias contratuais não reduzem ou alteram os usos sobre a utilização da terra pelos agricultores, os impactos produzidos sobre o território se encarregam de retirar do campo suas amenidades ambientais e um estilo de vida a que sua população estava habituada. Isso, por sua vez, contribui para resgatar ou, ainda, reforçar aspectos históricos da dinâmica de deslocamento populacional, como é o caso do êxodo rural.

Mostra-se necessário, portanto, reavaliar as políticas públicas de incentivo à produção de energia eólica quando os efeitos sociais e ambientais de sua ação corroboram a instalação de um cenário de injustiça ambiental que tende a afetar grupos sociais mais vulneráveis, como é o caso de agricultores familiares.

\section{Referências}

ACSELRAD, H. Justiça ambiental: ação coletiva e estratégias argumentativas. In. ACSELRAD, H; HERCULANO, S.; PÁDUA, J. A. (org.). Justiça ambiental e cidadania. Rio de Janeiro: Relume Dumará; Fundação Ford, 2004.

ACSELRAD, H.; MELLO, C. C. do A., BEZERRA, G. das N. O que é justiça ambiental. Rio de Janeiro: Garamond, 2009. ASSOCIAÇÃO BRASILEIRA DE ENERGIA EÓLICA (ABEEÓLICA). Boletim anual de geração de energia 2018. Bela Vista, SP: 2018. Disponível em: http://abeeolica.org.br/wp-content/uploads/2019/05/Boletim-Anual_2018.pdf. Acesso em: 17 abr. 2020.

BLOOMBERG NEW ENERGY FINANCE (BNEF); MINISTÉRIO DA CIÊNCIA, TECNOLOGIA E INOVAÇÕES (MCTI); ASSOCIAÇÃO BRASILEIRA DE ENERGIA EÓLICA (ABEEÓLICA). Energia eólica: os bons ventos para o Brasil. InfoVento, n. 7, 1 out. 2018. Disponível em: http://abeeolica.org.br/wp-content/uploads/2018/07/Infoventopt.pdf. Acesso em: 24 abr. 2020.

BRUNDTLAND, G. H. Relatório Brundtland: nosso futuro comum. [S. 1.]: Comissão Brundtland/ONU, 1987.

COSTA, H. S. "Negócios do vento" no Nordeste brasileiro: caso a investigar. Congresso em foco, Brasília, mar. 2018. Disponível em: https://congressoemfoco.uol.com.br/opiniao/colunas/\%E2\%80\%9Cnegocios-do-vento\%E2\%80\%9D-no-nordeste-brasileiro-caso-ainvestigar/. Acesso em: 13 abr. 2019.

FAIRHEAD, J.; LEACH, M.; SCOONES, I. Green Grabbing: a new appropriation of nature? The Journal of Peasant Studies, [S. 1.], v. 39, 2012. Disponível em: https://www.tandfonline.com/doi/full/10.1080/03066150.2012.671770?scroll=top\&needAccess=true. Acesso em: 24 abr. 2020.

FOLADORI, G. Limites do desenvolvimento sustentável. São Paulo: Impressa Nacional, 2001.

HANNINGAN, J. Sociologia ambiental. Petrópolis: Vozes, 2009.

MARTÍNEZ-ALIER, J. O ecologismo dos pobres: conflitos ambientais e linguagens de valoração. São Paulo: Contexto, 2007.

MONTIBELLER FILHO, G. O mito do desenvolvimento sustentável: meio ambiente e custos sociais no moderno sistema produtor de mercadorias. 2. ed. Florianópolis: Ed. da UFSC, 2004.

NERI, M. et al. Green versus green? Adverting potential conflicts between wind power generation and biodiversity conservation in Brazil. Perspectives in Ecology and Conservation, [S. 1.], v. 17, n. 3, p. 131-135, 2019.

O CASTIGO virou riqueza em forma de energia. Jornal do Comércio, Uol Nordeste Renovável, [São Paulo], 5 ago. 2018. Disponível em: http://especiais.jconline.ne10.uol.com.br/nordesterenovavel/panorama.php. Acesso em: 24 abr. 2020.

OLIVIERI, A. G. A teoria da modernização ecológica: uma avaliação crítica dos fundamentos teóricos. 2009. Tese (Doutorado) Programa de Pós-Graduação em Sociologia, Universidade de Brasília, DF, 2009. 
PARTE de torre eólica quebra e cai em Caetés, no Agreste. Rádio Jornal Pernambuco, Pernambuco, 23 jun. 2019. Disponível em: https://radiojornal.ne10.uol.com.br/noticia/2019/07/23/parte-de-torre-eolica-quebra-e-cai-em-caetes-no-agreste-173267. Acesso em: 24 abr. 2020.

PERNAMBUCO. População recenseada, por situação do domicílio. Governo do Estado de Pernambuco, Base de dados do estado, Pernambuco, 2007. Disponível em: http://www.bde.pe.gov.br/visualizacao/Visualizacao_formato2.aspx? codFormatacao=841\&CodInformacao=942\&Cod=3. Acesso em: 24 abr. 2020.

PORTO, M. F. Saúde pública e (in)justiça ambiental no Brasil. In: ACSELRAD, H.; HERCULANO, S.; PÁDUA, J. A. (org.). Justiça Ambiental e cidadania. Rio de Janeiro: 2004.

PORTO, M. F.; FINAMORE, R.; FERREIRA, H. Injustiças da sustentabilidade: Conflitos ambientais relacionados à produção de energia "limpa" no Brasil. Revista Crítica de Ciências Sociais, n. 100, p. 37-64, out. 2013. DOI 10.4000/rccs.5217.

SILVA, T. A. A. da. Percepção de risco e conflito socioambiental: um estudo sobre a instalação de um aterro sanitário em área de assentamento rural em Igarassu, Pernambuco. 2010. Tese (Doutorado)- Programa de Pós-Graduação em Sociologia, Universidade Federal de Pernambuco, Recife, Pernambuco, 2010.

TRALDI, M. Acumulação por despossessão: a privatização dos ventos para a produção de energia eólica no semiárido brasileiro. 2019. Tese (doutorado) -Universidade Estadual de Campinas, Instituto de Geociências, Campinas, São Paulo, 2019.

WANDERLEY, M de N. B. Identidade social e espaço de vida. In: WANDERLEY, M de N. B. Globalização e desenvolvimento sustentável: dinâmicas sociais no Nordeste brasileiro. São Paulo: Polis, 2004.

\section{Nota}

1 Por modernização ecológica Olivieri (2009, p. 57, grifo do autor) compreende, “[...] reparação de uma falha (defeito) do desenho estrutural da própria modernidade: a destruição institucionalizada da natureza". Para melhor compreensão da teoria consultar: Hanningan (2009) e Acselrad (2004)

\section{Amanda Oliveira de Santana}

rissardiamanda@gmail.com

Estudante de Ciências Sociais da Universidade Federal Rural de Pernambuco (UFRPE)

\section{Tarcísio Augusto Alves da Silva}

deescada@yahoo.com.br

Doutor em sociologia pela Universidade Federal Rural de Pernambuco (UFRPE)

Professor associado do Departamento de Ciências Sociais da Universidade Federal Rural de Pernambuco (UFRPE)

\section{UFRPE}

Rua Dom Manuel de Medeiros, s/n, Dois Irmãos

Recife/PE

CEP: 52171-900

\author{
Agradecimentos \\ Agradecemos aos estudantes da disciplina de Métodos \\ Qualitativos de Pesquisa Social (2019.1) do curso de \\ Bacharelado em Ciências Sociais da UFRPE que participaram \\ do processo de coleta de dados da pesquisa. \\ Agência financiadora \\ CNPq - Conselho Nacional de Desenvolvimento Científico \\ e Tecnológico. PIBIC - Programa Institucional de Bolsas de \\ Iniciação Científica (CNPq/UFRPE), número: 294, período de \\ execução Abril/2019 - Julho/2020
}

\author{
Contribuições das autoras \\ Tarcísio Augusto Alves da Silva: concepção, redação principal, \\ revisão do artigo. Amanda Oliveira de Santana: redação inicial \\ (introdução, tópico I), considerações finais. \\ Aprovação por Comitê de Ética e consentimento para \\ participação \\ Não se aplica. \\ Consentimento para publicação \\ Consentimento dos autores. \\ Conflito de interesses \\ Não há conflito de interesses.
}

